\title{
On the Lobbying Behavior Response to Political Asymmetries in International Economic Integration
}

\author{
I-Hui Cheng \\ National University of Kaohsiung
}

\begin{abstract}
The objective of this paper is to examine the effects of political asymmetries on a FTA and a CU. I have shown that either a higher lobbying sensitivity to the foreign firm or a more susceptibility of politicians to lobbying are sufficient to lead to a higher tariff protection at the individual country level. Under a $C U$, firms may dislike any form of political dominance in the common trade policy unless politicians do not discriminate against foreign lobbyists significantly. In contrast, under a FTA, if politicians are very susceptible to lobbying, the results appear to be ambiguous.
\end{abstract}

- JEL Classifications: D72, F13, F15

- Key words: Economic integration, Protection, Lobbying

\section{Introduction}

In general a political-economy model of trade policy, as Rodrik (1995) suggests, has two sides: the demand side and the supply side. The demand side of trade policy contains why and how individual preferences are gathered and channelled, and which available policy self-interested pressure groups ask for. They may continuously enjoy profits from protection by the reason of "social justice," i.e. protecting senescent industries or infant industries against foreign competitors. ${ }^{1}$ The political supply side

*Corresponding address: Professor I-Hui Cheng, Department of Applied Economics, National University of Kaohsiung, Nan-Tzu, Kaohsiung 811, Taiwan, ROC. Email: icheng@nuk.edu.tw (C)2003-Center for International Economics, Sejong Institution, All Rights Reserved.

${ }^{1}$ See Hillman (1982), Cassing and Hillman (1986), and Brainard and Verdier (1994, 1997). Also see Cassing and Hillman (1986), Rodrik (1986), Hillman and Ursprung (1988), and Moore and Suranovic (1992) for the choice between protectionist instruments. 
of trade policy contains politicians' preferences and the policy instruments which are used. As a result, self-interested politicians act in a manner that balances the marginal gain from the political support of lobbyist interests against the marginal loss to consumers.

The literature on political economy and trade has offered several explanations for the persistence of protection in terms of the interaction between declining industry, lobby, protection and self-interested politicians. Much of the earlier literature modelled the lobbying activities in a "political market" and small open economy, in which the domestic producers in import-competing industries would invest resources in lobbying for the protection until the marginal return on the last unit of contribution was equal to its probable return producing the transfer (see Bhagwati, 1980). The classical analysis of political and economic activities has focused on the rent- or revenue-seeking activities and their associated costs of distortions (see Krueger, 1974; Brock and Magee, 1978; Bhagwati and Srinivasan, 1980; Bhagwati, 1980).

A variety of models have been developed to extend research on the determination of domestic and international policies. One line of research has focused on domestic regulatory policy and trade policy formation. For example, Hillman (1982) adopts the Stigler-Peltzman assumption and uses a Ricardo-Viner framework in which government maximizes a political-support function by balancing the changes of the welfare of two competiting interest groups. Political support thus depends on the regulated domestic price level (see Stigler, 1971; Peltzman, 1976). ${ }^{2}$

A second line of research has emphasized the endogenous determination of trade policies through a political process. If voters in democratic societies are fully informed, the determination of trade policy would depend on the interests of the median voter (see Mayer, 1984). On the other hand, in a representative democracy framework, interest groups can probably enforce the lobbying pressure on bureaucrats or legislators to influence economic policies in favour of themselves. ${ }^{3}$ The approach recently developed in Grossman and Helpman (1994) combines elements of these two lines, in which profit-maximizing lobby groups make political

\footnotetext{
${ }^{2}$ See Hillman (1989) for a comprehensive survey of this approach. See also Long and Vousden (1991), and Choi (2001).

${ }^{3}$ Hillman (1989) and Riezman and Wilson (1995) review the literature. See also Brock and Magee (1978), Findlay and Wellisz (1982), Rodrik (1986), Young and Magee (1986), and Magee et al. (1989) for the political economy models.
} 
contributions to influence government policies, while the self-interested politicians maximize the objective function that is linear in social welfare and total contributions collected.

A third line of research has discussed the differences between two standard regional integration regimes: free trade agreements (FTA) and customs unions (CU). ${ }^{4}$ From the standpoint of a single firm or industry within a country, the benefits of protection can be significant and hence firms will have incentives to invest effort and money into the political process to secure their benefits. When countries form a trading bloc, one may also expect that firms would co-operate in their lobbying in order to influence trade policy in their favour and capture more profits in the larger (integrated) market. Thus, it is interesting to consider how interest groups, who lobby for or against specific trading agreements, will behave. Also, it is important to examine the political differences between different regimes of preferential trading agreements, in the presence of interest groups lobbying.

However, as noted by Krueger (1997a), in the former literature regarding political economy, there are few papers examining the differences between FTA and CU. Among key contributions to this are De Melo, Panagariya and Rodrik (1993), Richardson (1993, 1994), Cadot et al. (1996), Panagariya and Findlay (1996), Krueger (1997a), and Bandyopadhyay and Wall (1999).

The objective of this paper is to examine the effects of political asymmetries on a FTA and a CU. The term "political asymmetry" means either that individual governments interacting in a certain trading bloc respond to lobbying in different ways or that each government in a trading bloc responds to lobbying in the same way but treats foreign lobbyists in different ways. This paper considers two cases: the symmetric and discrimination-asymmetric cases. Regarding whether lobbyists have incentives to co-ordinate their lobbies in a FTA or a CU, it is necessary to consider three types of political environment. The first one is called the political symmetric environment in which not only are domestic and foreign politicians equally susceptible to lobbying, but they also deal with foreign lobbying pressures in the same way. The second case is the political response-asymmetric environment where the susceptibilities of the two governments to lobbying pressures are different, but politicians' attitudes to foreign lobbyists are identical. The third case is the political

\footnotetext{
${ }^{4}$ The conditions under which preferential trade arrangements are likely to be welfare-improving was first raised by J. Viner (1950). He introduced the key concepts of trade diversion and trade creation. Lipsey (1960) provides a survey of the classical theory of customs unions. Also see Jovanovic (1992), Hine (1994), and Baldwin and Venables (1995) for surveys of international economic integration.
} 
discrimination-asymmetric environment where governments are equally susceptible to lobbying, but they treat foreign lobbyists in different ways.

In contrast to Hillman and Ursprung (1988), this paper will also discuss the case of the lobbying co-ordination between firms inside the trading bloc. ${ }^{5}$ To simplify the model, this paper ignores the political response-asymmetric environment and freeriding problem. The rest of this paper is organised as follows. Section two presents the model and provides solutions to the co-operative lobbying problems under a FTA and a CU. In Sections Three and Four, concerning the incentives for lobbying cooperation, I will try to find the conditions under which a member-country firm has an incentive to co-operate its lobbying with a firm in another country under a FTA and under a CU respectively. Concluding remarks are offered in Section Five.

\section{A Two-Stage Model}

Assume that there are three countries - country 1, country 2 and the rest of the world (country 3, ROW), each with a firm producing a homogenous product. The price of the commodity is determined by firms competing with each other in the commodity market, with firms making Cournot-type conjectures. Suppose that the world market is geographically separated into three local domestic markets. The prices of the good may then differ between countries. Additionally, each country levies a tariff against firms from other countries. To obtain higher profits, firms' owners may choose to express their wishes to their own governments by lobbying. They may offer financial supports or contribution schedules to influence the domestic price.

The political game is a two-stage process. At the beginning of the first stage, each firm chooses the amount of lobbying contribution. Also, firms may co-operate with other firms in the industry to pursue higher profits. Suppose in the first stage only firms from countries 1 and 2 lobby, but firm 3 in ROW does not. This is reasonable, since it is more difficult for the supra-national government/institute of a FTA or a CU to resist lobbying from any firm inside the bloc. At the end of stage one, politicians set the optimal tariffs, responding to the amount of the lobby. However, ROW levies a tariff which is only determined by a welfare-maximising government. In stage two, given these tariffs and taking the Cournot-type conjecture, firms compete non-cooperatively and choose their optimal outputs for each market.

Assume that the inverse demand function of each country is identical and takes

${ }^{5}$ Hillman and Ursprung (1988) model the political competition in which foreign firms lobby domestic politicians in order to influence the trade policy in their favour. 
the following form:

$$
P_{j}=a-b Q_{j}, \quad j=1,2,3 ;
$$

where $Q_{j}=\Sigma_{i=1}^{3} x_{i j}$, and $x_{i j}$ is the volume of the good produced by firm $i$ and sold in country $j$. Having described the basic model, I move to the analysis.

\section{A. Stage Two}

Solving backwards, firm $i$ chooses its optimal output $x_{i j}$ for market $j$ to maximise $\pi_{i j}\left(x_{i j}\right)$ in the second stage. The basic assumption of the analysis here is that the tariff is employed to raise the profit of the industry. Countries 1 and 2 do not erect tariffs against the firms in the bloc, no matter which integration regime they undertake. Thus, the optimisation problems for both firms are the same under both the FTA and CU cases.

Assume there is only one firm from each country and the product market is segmented from each other. The three firms compete with each other in the three separate markets, and each firms total profit is the sum of individual profits from each market. As we know, since my model is of the Brander-Spencer type (1984) in this stage, there may be a strategic interaction between firms, e.g. explicit or tacit collusion. To keep the following analysis simple, any form of collusion is excluded from my model. The lobbying cost determined in stage one is an exogenous value in this stage, thus can be suppressed here. Also, since production is symmetric in the model, I just show the optimisation problem for firms interacting in country 1 below. Given a tariff $t_{1}$ chosen by government 1 in the first stage, the optimisation problem is for each of the three firms to maximise its own profits in the first market:

$$
\begin{gathered}
\operatorname{Max}_{X_{11}} \Pi_{11}\left(Q_{1}\right)=\left(a-b\left(x_{11}+x_{21}+x_{31}\right)-c\right) \cdot x_{11}, \\
\operatorname{Max}_{21} \Pi_{21}\left(Q_{1}\right)=\left(a-b\left(x_{11}+x_{21}+x_{31}\right)-c\right) \cdot x_{21}, \\
\underset{x_{31}}{\operatorname{Max}} \Pi_{31}\left(Q_{1}\right)=\left(a-b\left(x_{11}+x_{21}+x_{31}\right)-c-t_{1}\right) \cdot x_{31} ;
\end{gathered}
$$

where $x_{i j}$ denotes the volume of the good produced by the firm from country $i$ and sold in country $j$. The profit functions (excluding the cost of lobbying) for firms 1 and 2 in country 1 are shown (2-1) and (2-2) respectively; while the profit function of the non-member firm (firm 3), facing a tariff $t_{1}$, is represented in the equation (2-3). The solution to the above is:

$$
x_{11}^{*}=\frac{a-c+t_{1}}{4 b}, \quad x_{21}^{*}=\frac{a-c+t_{1}}{4 b}, \quad x_{31}^{*}=\frac{a-c-3 t_{2}}{4 b} .
$$


Obviously, each optimal output level is a function of the specific tariff $t$ : both $x_{11}^{*}$ and $x_{21}^{*}$ increase in the tariff level $t_{1}$, but $x_{31}^{*}$ decreases in $t_{1}$. Also, the volume of the commodity sold in country 1 is less than that without tariff protection. Without loss of generality, it is assumed that $(a-c)$ is positive.

Continuing to solve backwards, I will discuss the case in which firms 1 and firm 2 maximise their joint profits by co-ordinating their lobbying activities. Subsections B and $\mathrm{C}$ will present the solutions of the optimal lobbying levels for a FTA and a CU, respectively. Subsection D compares the tariff levels under a FTA and a CU.

\section{B. Stage One - Free Trade Area}

In the first stage, firms 1 and 2 choose their optimal lobbying levels. Following the "tariff-formation function approach" of Findlay and Wellisz (1982), I model the relationship between the amount of lobbying contribution that government 1 may receive and the resulting tariff $t_{1}$ as equation

$$
t_{1}=h_{1}\left(l_{11}, l_{21}\right)=\left(l_{11}+\gamma_{1} l_{21}\right) \cdot \delta_{1},
$$

where $t_{1}$ is the weighted sum of lobbying contributions from firm $1\left(l_{11}\right)$ and firm $2\left(l_{21}\right)$ multiplied by the lobbying influence on country 1 's tariff-setting $\left(\delta_{1}\right)$, and where $\gamma_{1}$ reflects the government 1 's sensitivity to firm 2's lobbying relative to that of firm 1. In this paper, $\delta_{1}$ and $\gamma_{1}$ are called as the lobbying response factor and discrimination factor respectively. Similarly, the relationship between country 2's tariff $t_{2}$ and the amount of lobbying contribution to government 2 can be represented as $t_{2}=h_{2}\left(l_{12}, l_{22}\right)=\left(\gamma_{2} l_{12}+l_{22}\right) \cdot \delta_{2}$. Government $j$ may entirely disregard foreign lobbyists, i.e. $\gamma_{j}=0$, or treat them as domestic lobbyists, i.e. $\gamma_{j}=$ 1. Thus, it is assumed that $0 \leq \gamma_{j} \leq 1$.

For simplicity, I assume the marginal cost of lobbies is constant and the lobbying cost function is identical across the trading bloc. Thus, firm $i$ 's cost of lobbying in country $j$ can be specified as $\Phi\left(l_{i j}\right)=\theta \cdot\left(l_{i j}\right)^{2} / 2 ; i, j=1,2$. Further, the total lobbying cost is simply assumed to be the summation of the cost that occurs in each country. Then, we can solve for the two cases under a FTA regime.

In this case, firms lobby to maximise their joint profits by optimally arranging their contributions to each government. The optimisation problems can be represented as

$$
\operatorname{Max} \sum_{l_{11}, l_{12}, l_{21}, l_{22}}^{2} \sum_{i=1}^{2} \pi_{i j}=\sum_{j=1}^{2} \frac{\left(a-c+h_{j}\left(l_{1 j}, l_{2 j}\right)\right)^{2}}{8 b}-\frac{\phi}{2} \sum_{i=1}^{2} \sum_{j=1}^{2}\left(l_{i j}\right)^{2}
$$

The profit from the market in country 3 for both firms is excluded from the 
optimisation problems in (5), since there is no lobbying activity in country 3 .

By using (4), the first-order conditions for problem (5) can be rearranged as:

$$
\gamma_{1}=\frac{l_{21}}{l_{11}} ; \quad \gamma_{2}=\frac{l_{12}}{l_{22}}
$$

The equations in (6) indicate politicians' attitudes to lobbying: government $j$ 's sensitivity to foreign lobbying $\left(\gamma_{j}\right)$ equals the ratio of the marginal cost of foreign firms lobbying to that of domestic firms lobbying in country $j$, and then equals the relative lobbying contributions to government $j$. By using (6) and the first-order conditions, it is straightforward to present the solution of the amount of optimal lobbying:

$$
\begin{array}{ll}
l_{11}^{F C}=\frac{(a-c) \delta_{1}}{4 b \phi-\left(1+\left(\gamma_{1}\right)^{2}\right) \cdot\left(\delta_{1}\right)^{2}}, & l_{12}^{F C}=\frac{(a-c) \gamma_{2} \delta_{2}}{4 b \phi-\left(1+\left(\gamma_{2}\right)^{2}\right) \cdot\left(\delta_{2}\right)^{2}}, \\
l_{21}^{F C}=\frac{(a-c) \gamma_{1} \delta_{1}}{4 b \phi-\left(1+\left(\gamma_{1}\right)^{2}\right) \cdot\left(\delta_{1}\right)^{2}}, & l_{22}^{F C}=\frac{(a-c) \delta_{2}}{4 b \phi-\left(1+\left(\gamma_{2}\right)^{2}\right) \cdot\left(\delta_{2}\right)^{2}}
\end{array}
$$

where the superscript "FC" indicates the co-operative lobbying case under the FTA regime. Country j's optimal tariff can then be represented as

$$
t_{j}^{F C}=\frac{(a-c)\left(1+\left(\gamma_{j}\right)^{2}\right)\left(\delta_{j}\right)^{2}}{4 b \phi-\left(1+\left(\gamma_{j}\right)^{2}\right)\left(\delta_{j}\right)^{2}}, \quad j=1,2 .
$$

Second-order conditions, $\left(\delta_{j}\right)^{2}-4 b \phi<0$, ensure that $l_{i j}^{F C}$ are $t_{i j}^{F C}$ optimally determined. Similarly, assume $\left(1+\left(\gamma_{j}\right)^{2}\right)\left(\delta_{j}\right)^{2}-4 b \phi<0$ to rule out the negative solution and ensure that $l_{i j}^{F C}$ and $t_{i j}^{F C}$ are positive.

\section{Stage One - Customs Union}

As under the FTA regime, outputs are determined by the competition between firms involved in each market, i.e. output decisions are made at the firm level. However, since both governments take part in the tariff decision, lobbying decisions in this stage are at the CU level. Following the ideas of Rodrik (1986), and Bandyopadhyay and Wall (1999), I assume that the common tariff takes a very simple linear form:

$$
t^{C U}\left(l_{11}, l_{12}, l_{21}, l_{22}\right)=\theta h_{1}\left(l_{11}, l_{21}\right)+(1-\theta) h_{2}\left(l_{12}, l_{22}\right), \quad 0 \leq \theta \leq 1
$$

where $\theta$ reflects government 1 's share of influence on tariff-setting, and $h_{j}\left(l_{1 j}, l_{2 j}\right)$ are defined in equation (4). In the $\mathrm{CU}$, the tariff setting may entirely depend on 
government 1's attitude when $\theta=1$, or government 2 's when $\theta=0$. Otherwise, it is determined by the bargaining power between member governments. The specific form of equation (9) is then

$$
t^{C U}\left(l_{11}, l_{12}, l_{21}, l_{22}\right)=\theta \delta_{1}\left(l_{11}, \gamma_{1} l_{21}\right)+(1-\theta) \delta_{2}\left(\gamma_{2} l_{12}+l_{22}\right) .
$$

The optimisation problems are similar to those in subsection B, except the need to replace $h_{j}\left(l_{1 j}, l_{2 j}\right)$ with $t^{C U}($.$) .$

By maximising the joint profits, each firm decides how much it should contribute at each country level. The optimisation problem can be represented as:

$$
\operatorname{Max} \sum_{l_{11}, l_{12}, l_{21}, l_{22}}^{2} \sum_{i=1}^{2} \pi_{i j}=\frac{\left(a-c+t^{C U}(.)\right)^{2}}{4 b}-\frac{\phi}{2} \sum_{i=1}^{2} \sum_{j=1}^{2}\left(l_{i j}\right)^{2}
$$

Using (10) and maximising (11) with respect to the individual amount of lobbying yields the first-order conditions which are shown in Appendix A. First, rearranging those terms yields an expression relating the discrimination factor, the response factor and the marginal cost of lobbying, which is identical to that in equation (6). Additionally, we know that firm 1's lobbying behaviour follows

$$
\frac{l_{11}}{l_{12}}=\frac{\theta}{1-\theta} \frac{\delta_{1}}{\gamma_{2} \delta_{2}}
$$

Equation (12) demonstrates how firm 1 distributes its contributions to member countries. Should the bargaining power of the domestic government be stronger, each firm would be willing to contribute to its government more. Firm 2's behaviour is symmetric and then suppressed here. The optimal amounts of lobbying in the first stage under a CU are:

$$
\begin{array}{ll}
l_{11}^{c c}=\frac{(a-c) \theta \delta_{1}}{2 b \phi-A} ; & l_{12}^{c c}=\frac{(a-c)(1-\theta) \delta_{2} \gamma_{2}}{2 b \phi-A} ; \\
l_{2 \mathrm{~F}}^{c c} \frac{(a-c) \theta \delta_{1} \gamma_{1}}{2 b \phi-A} ; & l_{22}^{c c}=\frac{(a-c)(1-\theta) \delta_{2}}{2 b \phi-A} ;
\end{array}
$$

where $A=\theta^{2}\left(\delta_{1}\right)^{2}\left(1+\left(\gamma_{1}\right)^{2}\right)+(1-\theta)^{2}\left(\delta_{2}\right)^{2}\left(1+\left(\gamma_{2}\right)^{2}\right)$, and the superscript "CC" denotes co-operative lobbying under the $\mathrm{CU}$ regime. By substituting equations in (13) into (10), I have the level of tariff:

$$
t^{C C}=\frac{(a-c) A}{2 b \phi-A} .
$$


The second-order conditions for problem (11) are $\theta_{2}\left(\delta_{1}\right)^{2}-2 b \phi<0$ and $(1-\theta)^{2}\left(\delta_{2}\right)^{2}$ $-2 b \theta<0$. Again, the sufficient condition for a feasible positive solution to the system is $2 b \phi-A>0$, i.e. assume $\theta^{2}\left(\delta_{1}\right)^{2}\left(1+\left(\gamma_{1}\right)^{2}\right)+(1-\theta)^{2}\left(\delta_{2}\right)^{2}\left(1+\left(\gamma_{2}\right)^{2}\right)-2 b \phi<0$.

\section{Tariff Comparison between a FTA and a CU- An Example of the Co- operative Lobbying Case}

According to (8) and (14), the optimal lobbying and tariff both increase in the response factor $\left(\delta_{j}\right)$ and the discrimination factor $\left(\gamma_{j}\right)$ under both the FTA and the $\mathrm{CU}$ regimes, but decrease in the production cost $(c)$, the slope of demand function $(b)$, and the marginal cost of lobbying $(\phi)$. Also, the market share of member firms increases in $\gamma_{j}$ and $\delta_{j}$. This result reflects the basic setup of the model in which politicians and interest groups follow the patterns of decision-making on lobbying and tariff in the equations in (4) and (9).

Before I look into firms' incentives to co-ordinate their lobbying, it is interesting to find the condition under which a $\mathrm{CU}$ is likely to be more protective, i.e. a CU tariff is higher than a FTA tariff. Regarding this issue, let us now use an example of the co-operative lobbying case. Using (8) and (14) obtains the condition under which the $\mathrm{CU}$ tariff is greater than both countries tariff levels:

$$
\Gamma_{2} \equiv \frac{1-2(1-\theta)^{2}}{2 \theta^{2}}<\left(\frac{\delta_{1}}{\delta_{2}}\right)^{2} \frac{1+\left(\gamma_{1}\right)^{2}}{1+\left(\gamma_{2}\right)^{2}}<\frac{2(1-\theta)^{2}}{1-2 \theta^{2}} \equiv \Gamma_{1} \text {. }
$$

The $\Gamma_{j}$ curve in Figure 1 illustrates the equivalence of country $j$ 's tariff in a FTA and in a CU. For political environments that lie in areas $\mathbf{C}$ and $\mathbf{D}$, the $\mathbf{C U}$ tariff is greater than both countries tariff in a FTA, i.e. $t^{C U}>t_{1}$ and $t^{C U}>t_{2}$. Otherwise, a CU would see that its tariff is higher than one countrys tariff but lower than the others, since the tariff system in a CU takes the form of linearity weighed by the bargaining power of each member country: for area $\mathbf{A}, t_{2}<t^{C U}<t_{1}$, and for area $\mathbf{B}, t_{1}<t^{C U}<t_{2}$.

There are two points of interest in Figure 1. First, the point of tangency $\mathbf{e}$ at which $\left(1+\left(\gamma_{1}\right)^{2}\right)\left(\gamma_{1}\right)^{2}=\left(1+\left(\gamma_{2}\right)^{2}\right)\left(\delta_{2}\right)^{2}$ and $\theta=1 / 2$ suggests that neither country will see a higher tariff after they form a CU when political environments are perfectly symmetric, i.e. $\delta_{1}=\delta_{2}, \gamma_{1}=\gamma_{2}$, and, $\theta=1 / 2$ or when the weighted political conditions in each country are identical, e.g. $\gamma_{j}=0, \gamma_{-j}=1, \delta=\sqrt{2} \delta_{-j}$, and $\theta=1 / 2$. The implication for the latter case is as follows. Suppose a local government that cares little for foreign firms' interests but is more susceptible to lobbying forms a CU with a foreign government that treats domestic and foreign lobbyists the same but is less susceptible to lobbying. In the presence of the equivalence of each country's 
Figure 1. The Tariff Comparison.

Area A: $t_{2}<t^{C U}<t_{1}$; Area B: $t_{1}<t^{C U}<t_{2}$; Areas C and D: $t^{C U}>t_{1}$ and $t^{C U}>t_{2}$. In the Figure, $R_{1}=1+\left(\gamma_{1}\right)^{2}$ and $R_{2}=1+\left(\gamma_{2}\right)^{2}$.

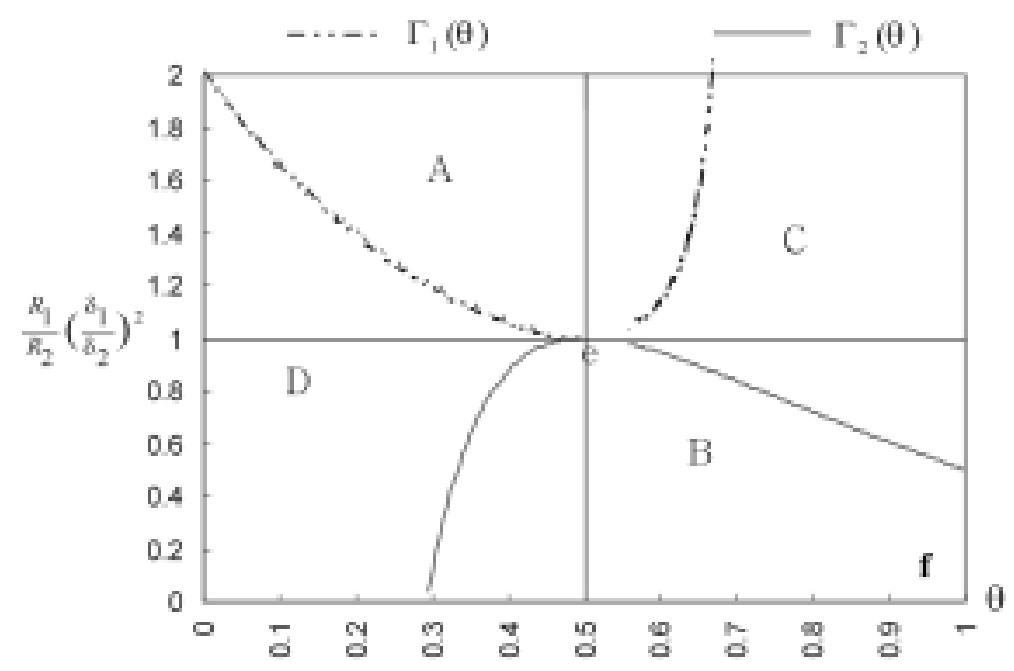

bargaining power over tariff setting, they will see the common tariff is as the same as individual tariffs in a FTA.

Second, consider the political environment of point $\mathbf{f}$ at which $\theta=1$ and $\delta_{1}=0$. In this case, the common tariff-setting is completely dominated by a government of trade liberalism, government 1 . As a result, the common tariff in a CU would equal country 1 's tariff in a FTA, which is zero. ${ }^{6}$

\section{The Political Environments for the Co-operation in Lobbying}

\section{A. Under the FTA Regime}

Due to the symmetric setup, the comparison of lobbying benefits in the following is just shown for firm 1. Using (7) and (8), I derive the profit functions for firm 1:

$$
\begin{aligned}
& \pi_{1}^{F N}=\frac{\phi(a-c)^{2}}{2}\left(\frac{8 b \phi-\left(\delta_{1}\right)^{2}}{8 b \phi-\left(\left(1+\left(\gamma_{1}\right)^{2}\right)\left(\delta_{1}\right)^{2}\right)^{2}}+\frac{8 b \phi-\left(\gamma_{2}\right)^{2}\left(\delta_{2}\right)^{2}}{8 b \phi-\left(\left(1+\left(\gamma_{2}\right)^{2}\right)\left(\delta_{2}\right)^{2}\right)^{2}}\right) \\
& \pi_{1}^{F N}=\frac{\phi(a-c)^{2}}{2}\left(\frac{2 b \phi-\left(\delta_{1}\right)^{2}}{4 b \phi-\left(\left(1+\left(\gamma_{1}\right)^{2}\right)\left(\delta_{1}\right)^{2}\right)^{2}}+\frac{2 b \phi-\left(\gamma_{2}\right)^{2}\left(\delta_{2}\right)^{2}}{4 b \phi-\left(\left(1+\left(\gamma_{2}\right)^{2}\right)\left(\delta_{2}\right)^{2}\right)^{2}}\right)
\end{aligned}
$$

${ }^{6}$ For more alternative discussion, see also Bandyopadhyay and Wall (1999). 
where $\pi_{1}^{F N}$ and $\pi_{1}^{F C}$ indicate firm 1's profit under the non-co-operative lobbying and the co-operative lobbying cases respectively. I will compare $\pi_{1}^{F N}$ with $\pi_{1}^{F C}$ for two cases: the symmetric and the discrimination-asymmetric cases. The relevant net benefit functions for these cases are shown in the equations in (A2)-(A3) in Appendix B. Note, the term "net benefit" of firm $i$ measures the profit added by firms' co-operation in lobbying. Also, in the results below, all numerical simulations have demand parameters: $a=5, b=1$, and cost parameters are $c=\phi=1$.

\section{The Symmetric Case}

Consider the case in which the political environments for lobbyists are symmetric, i.e. $\delta_{1}=\delta_{2}=\delta$ and $\gamma_{1}=\gamma_{2}=\gamma$. By using the equations in (16) and (17), the relevant expression of the net benefit for firm 1 can be represented as:

$$
\operatorname{sgn}\left\{\pi_{1}^{F C}-\pi_{1}^{F N}\right\}=\operatorname{sgn}\left\{\frac{\left(1+\gamma^{2}\right) \delta^{2}}{\left(4 b \phi-\left(1+\gamma^{2}\right) \delta^{2}\right)\left(8 b \phi-\left(1+\gamma^{2}\right) \delta^{2}\right)^{2}}\right\}, \gamma \in[0,1]
$$

A positive sign in equation (18) means firm 1 can benefit from co-ordinating lobbying with firm 2 . Since we need to assume $\left(1+\left(\gamma_{j}\right)^{2}\right)\left(\delta_{j}\right)^{2}<4 b \phi$ and $\left(1+\left(\gamma_{j}\right)^{2}\right)\left(\delta_{j}\right)^{2}<8 b \phi$ to rule out the negative solutions to the co-operative lobbying and the non-co-operative cases under a FTA. As a result, the right-hand side of (18) is always non-negative. Also note that in this case firm 2's net benefit from co-ordinating lobbying is the same as firm 1's. Thus, membercountries' firms in the FTA regime would be willing to co-operate lobbying with each other.

The right-hand side of (18) also depicts that the benefit from co-ordinating lobbying, $\pi_{1}^{F C}-\pi_{1}^{F N}$, increases in $\delta$ and $\gamma$. That is, the more susceptible politicians are to lobbies (e.g. a large $\delta$ ), the more benefit firms may have from co-operating in lobbying. Also, the less domestic governments discriminate against foreign lobbyists (e. g. $\gamma \rightarrow 1$ ), the more benefit firms expect to have from co-ordinating their lobbying, except when politicians reject all lobbying, i.e. $\delta=0$.

\section{The Discrimination-Asymmetric Case}

I now consider the discrimination-asymmetric case in which member governments are equally susceptible to lobbying (e.g. $\delta_{1}=\delta_{2}=\delta$ ), but their attitudes to foreign interest groups are different (e.g. $\gamma_{1} \neq \gamma_{2}$ ). By plugging $\delta$ into (16) and (17), the relevant expression of the net benefit of firm 1 from cooperating lobbying can be represented as: 


$$
\begin{aligned}
\operatorname{sgn}\left\{\pi_{1}^{F C}-\pi_{1}^{F N}\right\}=\operatorname{sgn}\left\{\delta ^ { 2 } \left(\frac{8 b \phi\left(2\left(\gamma_{1}\right)^{2}-1\right)-\left(3\left(\gamma_{1}\right)^{2}-1\right)\left(1+\left(\gamma_{1}\right)^{2}\right) \delta^{2}}{\left(\left(4 b \phi-\left(1+\left(\gamma_{1}\right)^{2}\right) \delta^{2}\right)\left(8 b \phi-\left(1+\left(\gamma_{1}\right)^{2}\right) \delta^{2}\right)\right)^{2}}\right.\right. \\
\left.+\frac{8 b \phi\left(2-\left(\gamma_{2}\right)^{2}\right)-\left(3-\left(\gamma_{2}\right)^{2}\right)\left(1+\left(\gamma_{2}\right)^{2}\right) \delta^{2}}{\left(\left(4 b \phi-\left(1+\left(\gamma_{2}\right)^{2}\right) \delta^{2}\right)\left(8 b \phi-\left(1+\left(\gamma_{2}\right)^{2}\right) \delta^{2}\right)\right)^{2}}\right), \quad \gamma_{j} \in[0,1] .
\end{aligned}
$$

When politicians reject all lobbying (i.e. $\delta=0$ ), the right-hand side of (19) equals zero. That is, the net profits from co-operating and non-co-operating lobbying are indifferent. Based on simulation results, for this case a rise in the lobby-response factor $\delta$ may increase firm 1's incentives to co-ordinate lobbying in general, if $\delta$ is not too large. However, when the response factor $\delta$ is too large, firms' incentives to co-ordinate their lobbying may also depend on the values of the discrimination factors $\gamma_{1}$ and $\gamma_{2}$. To further explain the idea, I now offer two examples: $\delta=1$ and $\delta=1.5$.

For the case where $\delta$ is not too large, e.g. $\delta=1$, the graph of the function in the right-hand side of (19) can be illustrated as in Figure 2. As one can see, firm 1 is always willing to co-operate in lobbying with firm 2 . Given a $\gamma_{2}$, a rise in $\gamma_{1}$ increases firm 1's net benefit. The result implies that the less domestic politicians discriminate against foreign lobbyists (i.e. a rise in $\gamma_{1}$ ), the more lobbying contributions the domestic government can get from interest groups, and then erect a higher tariff against outsiders. As a result, the domestic firm is more willing to co-operate in lobbying with the foreign firm to capture more profit. Also according to these simulations, given a $\gamma_{1}$, firm 1's lobbying benefit from co-operation increases in $\gamma_{2}$ when $\gamma_{2}$ is less than $0.73 \sim 0.75$, and then decreases in $\gamma_{2}$.

For the case where $\delta$ is large, e.g. $\delta=1.5$, the relationship between firm 1's net benefit from co-operation and the discrimination factors $\left(\gamma_{j}\right)$ is more complicated. Based on the simulation result, firm 1's benefit from lobbying co-operation increases in $\gamma_{2}$, given a $\gamma_{2}$; while it decreases in $\gamma_{1}$, given a $\gamma_{2}$. Note that the secondorder conditions rule out the range $0.88<\gamma_{j} \leq 1$. The graph of the function in the right-hand side of (19) is illustrated in Figure 3, noting that the axes of $\gamma_{1}$ and $\gamma_{2}$ are located differently from those in Figure 2. As I have found, firm 1 is willing to co-ordinate lobbying with firm 2, except in the case where the political environment is located within area D. For the case where both $\gamma_{1}$ and $\gamma_{2}$ are large, e.g. $\gamma_{j} \in[0.72,0.88]$, the result is reported in Table 1. One would be aware that firm 1 can capture an extremely high benefit from co-operation in lobbying when both 
Figure 2. The Discrimination-Asymmetric Case under a FTA:

$\gamma_{1} \neq \gamma_{2}$ and $\delta=1$.

A positive but not too large value of $\delta($ e.g. $\delta=1)$ increases firms' incentives to co-operate. The figure shows that firm 1 is always willing to co-operate in lobbying with the other member firm. The other parameters here are $a=5, b=1, c=1, \phi=1$.

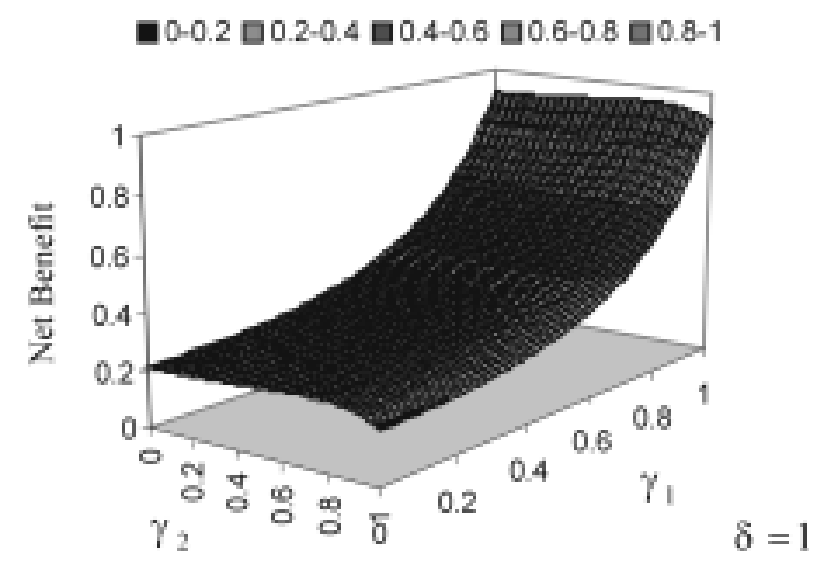

$\gamma_{1}$ and $\gamma_{2}$ are very large, but the net benefit is very sensitive to the asymmetry of the discrimination factors, i.e. $\left|\gamma_{1}-\gamma_{2}\right|$. In fact, firm 1's benefit from co-operating in lobbying significantly increases in $\left(\gamma_{2}-\gamma_{1}\right)$ in this case.

One implication of the discrimination-asymmetric case under the FTA regime is that lobbyists prefer to face the political symmetry if co-operation in lobbying is allowed. As one can see in Figures 2 and 3, areas near the dotted curves consist of all the political environments for which both firms' net profits from co-operation in lobbying are nearly equivalent and always non-negative. Unless the compensated transfer of lobbying benefit between lobbyists is allowed, a deviation far away from the dotted curve may lead to significantly unbalanced profits between both firms in the case of a small $\delta$, or results in one firm enjoying a large benefit while the other firm suffers in the case of a large $\delta$.

\section{B. Under the CU Regime}

This section compares firm 1s profit under the non-co-operative lobbying case and the co-operative lobbying case in the $\mathrm{CU}$ regime. Now use the equations in (10), (13) and (14) to obtain for firm 1s profit functions:

$$
\pi_{1}^{C N}=\frac{\phi(a-c)^{2}}{2(2 b \phi-A)^{2}}\left(b \phi-\left(\theta \delta_{1}\right)^{2}-\left((1-\theta) \gamma_{2} \delta_{2}\right)^{2}\right),
$$


Figure 3. The Discrimination-Asymmetric Case under a FTA: $\gamma_{1} \neq \gamma_{2}$ and $\delta=1.5$.

A large value of $\delta$ (e.g. $\delta=1.5$ ) may lead to an ambiguous result. For this case, given a smaller $\gamma_{1}$ and a larger $\gamma_{2}$, firm 1 may have strong incentives to co-operate in lobbying with firm 2. The other parameters here are $a=5, b=1, c=1, \phi=1$. Also see Table 1 for the case where both $\gamma_{1}$ and $\gamma_{2}$ are large.

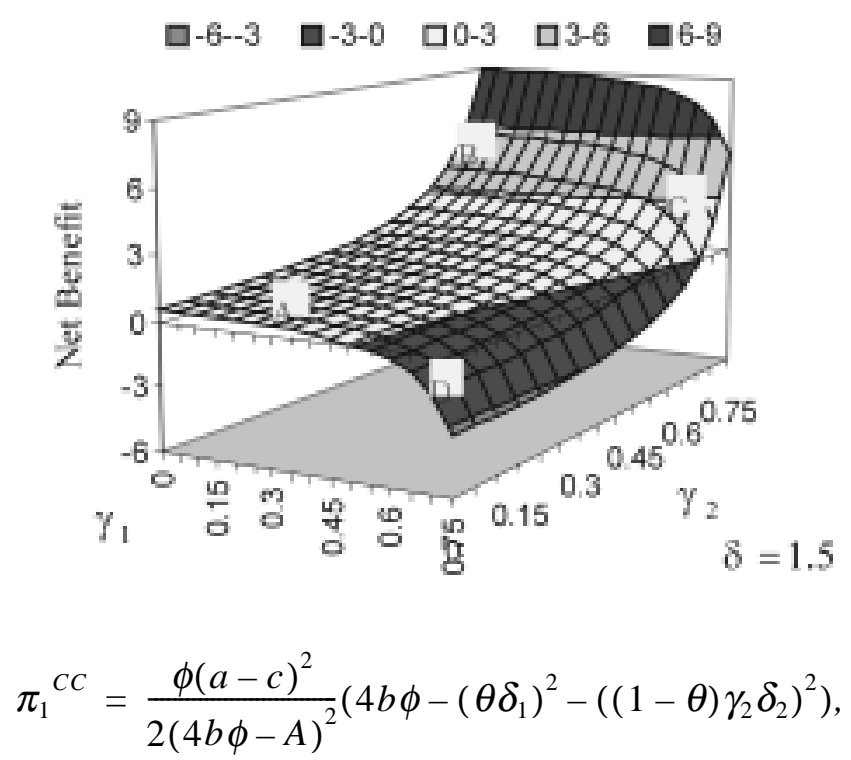

where the superscripts " $\mathrm{CN}$ " and "CC" denote the non-co-operative and cooperative lobbying cases under the $\mathrm{CU}$ regime, respectively. The relevant net profit functions for these cases are shown in the equations in (A4)-(A5) in Appendix C.

\section{The Symmetric Case}

Now, consider the case in which the political environments for lobbyists are symmetric except for asymmetry in bargaining power $(\theta)$, i.e. $\delta_{1}=\delta_{2}=\delta$ and $\gamma_{1}=$ $\gamma_{2}=\gamma$. Then using the equations in (20) and (21), we have the relevant expression of the net benefit for firm 1 :

$$
\begin{gathered}
\operatorname{sgn}\left\{\pi_{1}^{C C}-\pi_{1}^{C N}\right\}=\operatorname{sgn}\left\{\left(4 b \phi\left(2-\gamma^{2}\right)(1-2 \theta)+\left(1+\gamma^{2}\right) \theta^{2}\right)\right. \\
\left.\left.-\left(\left(3-\gamma^{2}\right)(1-2 \theta)+2\left(1+\gamma^{2}\right) \theta^{2}\right)\left(\theta^{2}+(1-\theta)^{2}\right) \delta^{2}(1+\gamma)^{2}\right) \delta^{2}\right\} ; \gamma, \theta \in[0,1] .
\end{gathered}
$$

When $\delta=0, \theta_{1}^{C C}-\theta_{1}^{C N}=0$ : under the political environments in which policymakers do not care for interest groups at all, firms' benefits from non-co-operating and co-operating in lobbying are equivalent. From (22), if $\delta>0, \gamma=1$, and the 
second-order condition for the CU regime is satisfied, firms are willing to cooperate in lobbying. Otherwise, the situation depends on the values of the parameters, $\delta, \theta$ and $\gamma$, in the model.

Suppose each country's bargaining power to set the common tariff is identical, i.e. $\theta=1 / 2$. Then, the right-hand side of (22) can be simplified as $1 / 4 \cdot(1+$ $\left.\gamma^{2}\right) \delta^{2}\left(4 b \phi-\left(1+\gamma^{2}\right) \delta^{2}\right)$, which satisfies the second-order condition, being always positive. That is, for political environments in which the $\mathrm{CU}$ member countries are equally susceptible to lobbying and have the same power to set up a common tariff, lobbyists should be always willing to co-ordinate their lobbying to capture more profit.

Consider the case where foreign government dominates the common trade policy of the $\mathrm{CU}$, i.e. $\theta=0$. From (22), the domestic firm would like to co-operate whenand the second-order condition " $\delta^{2}<2 b \phi /\left(1+\gamma^{2}\right)$ " are satisfied. Since $4 b \phi$ $\left(2-\gamma^{2}\right) /\left(\left(3-\gamma^{2}\right)\left(1+\gamma^{2}\right)\right)$ is greater than $2 b \phi /\left(1+\gamma^{2}\right)$ except when $\gamma=1$, the domestic firm is always willing to co-operate in lobbying. In contrast, suppose the domestic government dominates in the CU, i.e. $\theta=1$. From (22), the domestic firm would like to co-operate in lobbying with the other firm only when $\left(3 \gamma^{2}-1\right)(1$

Figure 4. The Symmetric Case under a CU:

$\delta_{1}=\delta_{2}=\delta ; \gamma_{1}=\gamma_{2}=0.75$.

The symmetric case under the CU regime: $\gamma=0.75$. Points in areas $\mathbf{C}$ and $\mathbf{N}$ satisfy the secondorder condition (S.O.C.), and in areas $\mathbf{U}$ and $\mathbf{C} \pi_{1}^{C C}-\pi_{1}^{C N}>0$. Thus, area $\mathbf{C}$ consists of all the political environments for which firm 1 wants to co-operate in lobbying with firm 2 . In area $\mathrm{N}$, firm 1 refuses to co-operate. The other parameters here are $a=5, b=1, c=1, \phi=1$.

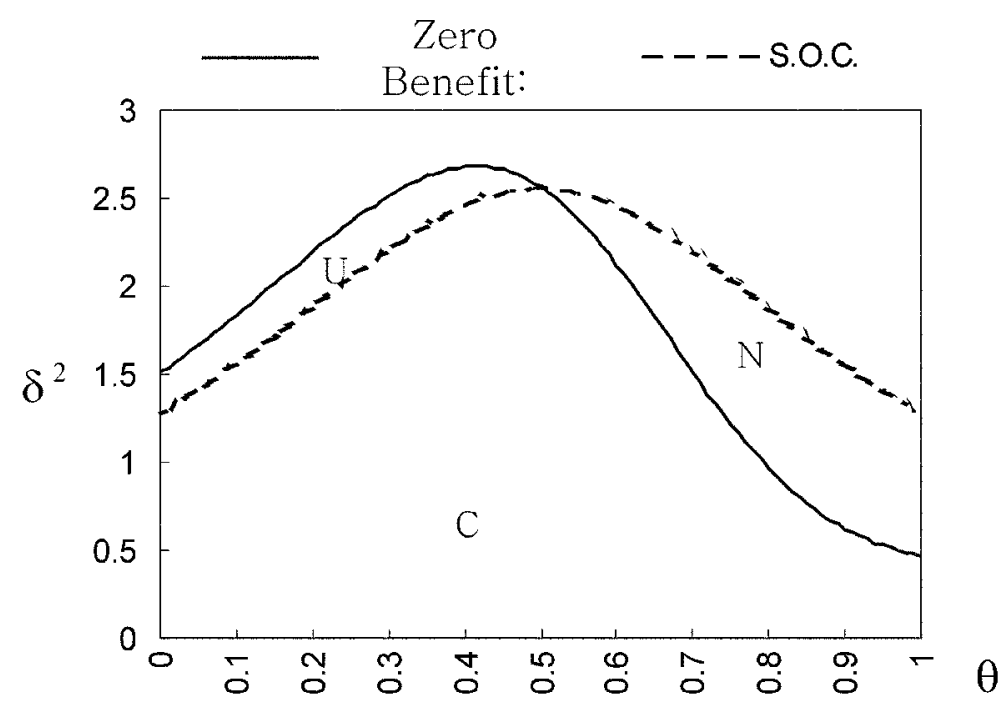


Figure 5. The Symmetric Case under a CU:

$\delta_{1}=\delta_{2}=\delta ; \gamma_{1}=\gamma_{2}=0.25$.

The symmetric case under the CU regime: $\gamma=0.25$. Points in areas $\mathbf{C}, \mathbf{C}^{*}$ and $\mathbf{N}$ satisfy $\pi_{1}^{C C}$ $\pi_{1}^{C N}>0$, but only area $\mathbf{C}$ consists of all the political environments for which firm 1 wants to co-operate in lobbying with firm 2 . In area $\mathbf{N}$, firm 1's profit is negative, co-operation in lobbying is not feasible. The other parameters here are $a=5, b=1, c=1, \phi=1$.

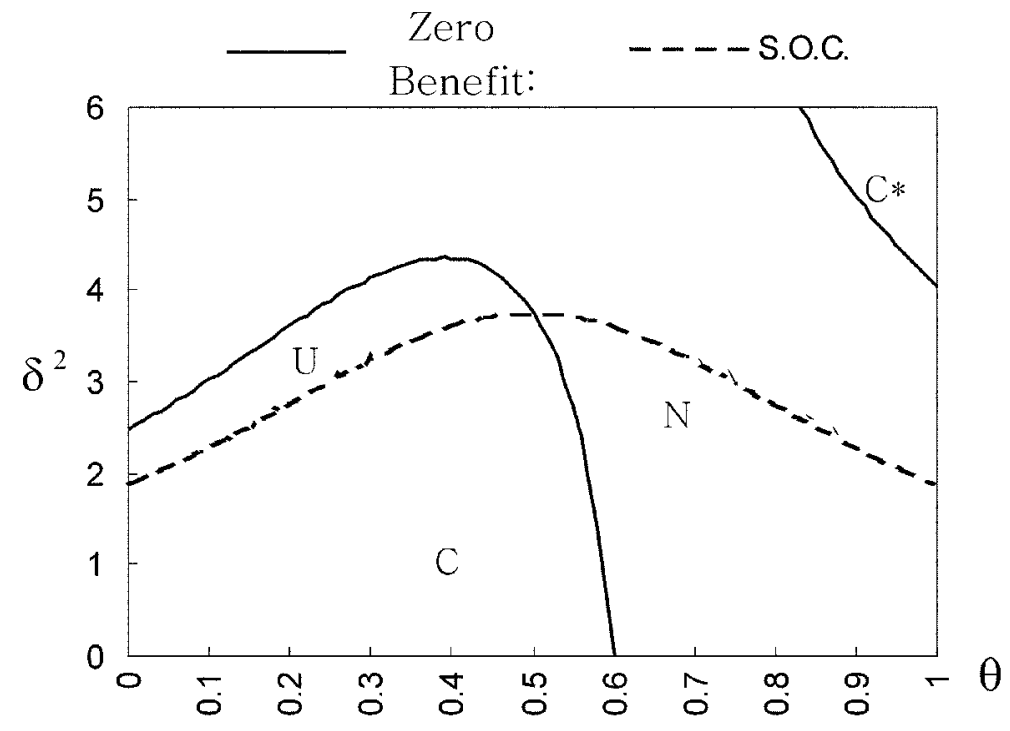

$\left.+\gamma^{2}\right) \delta^{2}<4 b \phi\left(2 \gamma^{2}-1\right)$ and $\delta^{2}<2 b \phi /\left(1+\gamma^{2}\right)$. As a result, in political environments where politicians do not discriminate against foreign firms significantly, e.g. $0.707<\gamma \leq 1$, and if $\delta^{2}<\frac{4 b \phi\left(2 \gamma^{2}-1\right)}{\left(1+\gamma^{2}\right)\left(3 \gamma^{2}+1\right)}$, firms should be willing to co-operate
in lobbying.

For the general case where member governments' bargaining powers in tariffsetting in a CU are unequal, Figures 4 and 5 show the graphs of (22) for two values of the discrimination factor, i.e. $\gamma=0.75$ and $\gamma=0.25$. The values of the other parameters used in my simulations are $a=5, b=1, c=1$, and $\phi=1$. Each solid curve on these figures corresponds to the zero benefit of firm 1 . The boundaries of the second-order condition are shown by the dotted curves. In Figure 4, points under the zero-benefit and the second-order condition curves, area C, represent all the political environments for which co-operation in lobbying benefits firm 1 , when $\gamma=0.75$. In contrast, the zero-benefit curve of firm 1 is a pair of hyperbola when $\gamma=0.25$. In Figure 5, points in areas $\mathbf{C}, \mathbf{U}$, and $\mathbf{C}^{*}$ satisfy $\pi_{1}^{C C}-$ $\pi_{1}^{C N}>0$, but only for the environments in area $\mathbf{C}$ firm 1 would try to co-operate in lobbying. Also, based on simulations, the zero-benefit curve of lobbying flatters 
when $\gamma$ increases. For the case $\gamma=1$ where politicians absolutely treat foreign firms as domestic firms, because of the symmetry of the setup, firms can be expected to co-operate with each other.

\section{The Discrimination-Asymmetric Case}

Now let us examine the discrimination-asymmetric case, i.e. $\delta_{1}=\delta_{2}=\delta$ but $\gamma_{1}$ $\neq \gamma_{2}$, under the CU regime. Using (20) and (21), and replacing and with to obtain the relative expression of the net benefit from co-operating lobbying for firm 1 :

$$
\begin{gathered}
\operatorname{sgn}\left\{\pi_{1}^{C C}-\pi_{1}^{C N}\right\}=\operatorname{sgn}\left\{\left(4 b \phi\left(2\left(\gamma_{1}\right)^{2}-1\right) \theta^{2}+\left(2-\left(\gamma_{2}\right)^{2}\right)(1-\theta)^{2}\right)-\right. \\
\left.\left.\left(\left(3\left(\gamma_{1}\right)^{2}-1\right) \theta^{2}+\left(3-\left(\gamma_{2}\right)^{2}\right)(1-\theta)^{2}\right) \bar{A}\right) \delta^{2}\right\}, \gamma_{j}, \theta \in[0,1]
\end{gathered}
$$

where $\bar{A}=\left(\theta^{2}\left(1+\left(\gamma_{1}\right)^{2}+(1-\theta)^{2}\left(1+\left(\gamma_{2}\right)^{2}\right)\right) \delta^{2}\right.$. When $\delta=0$, the right-hand side of (23) equals zero. That is, when politicians ignore lobbying pressures from foreign interest groups, a firm's profits under the non-co-operative and the cooperative cases are identical. When $\delta>0$, a firm's net benefit from co-ordinating lobbying would depend on $\gamma_{1}, \gamma_{2}, \delta$ and $\theta$.

To keep things simple, let $\gamma_{1}=1$. Then, the numerical value of $\gamma_{2}$ here would indicate the sensitivity of government 2 to firm 1's lobbying relative to that of government 1 to firm 2's. As a result, from (23) it can be seen that a domestic firm would prefer to co-operate lobbying when:

$$
\left(\gamma_{2}\right)^{2}<\left(\left(2 b \phi+(1-\theta)^{2} \delta^{2}\right)-\sqrt{\left(\left(2 b \phi+(1-\theta)^{2} \delta^{2}\right)\right)^{2}-\delta^{2} B}\right) /((1-\theta) \delta)^{2},
$$

where $B=4 b \phi\left(\theta^{2}+2(1-\theta)^{2}\right)-\left(2 \theta^{2}+(1-\theta)^{2}\right)\left(2 \theta^{2}+3(1-\theta)^{2}\right) \delta^{2}$. Also the second order condition ensuring positive values of the amount of lobbying and the common tariff in this case is: $\left(\gamma_{2}\right)^{2}<\left(2 b \phi-\left(\theta^{2}+(1-\theta)^{2} \delta^{2}\right) /(1-\theta) \delta\right)^{2}$.

To avoid confusion, I focus the numerical values of $\left(\gamma_{2}\right)^{2}$ on the range from zero to one. In Figure 6, I present an example where $\delta=1.5$ in which the solid curve and the dotted line trace out the zero-benefit function of firm 1 from co-operating lobbying and the second-order condition under this case, respectively. As one can see, only points in area $\mathbf{C}$ contain all the political environments for which co-operative lobbies benefit firm 1. A move downwards from point $\mathbf{R}$ at which corresponds to $\left(\gamma_{2}\right)^{2}=0.781$ (i.e. $\gamma_{2}$ $=0.88$ ) and $\theta=0.45$ leads to a rise in firm 1's benefit from co-operative lobbying.

As in the FTA regime, the results of the discrimination-asymmetric case under the CU regime imply that interest groups could easily co-ordinate their lobbying in the political environments where lobbying is overall symmetric across the 
Figure 6. The Discrimination-Asymmetric Case under a CU: $\delta_{1}=\delta_{2}=\delta=1.5 ; \gamma_{1}=1$.

Points in areas $\mathbf{C}$ and $\mathbf{U}$ consist of all the po environments for which firm 1 wants to cooperate in lobbying with firm 2: $p_{1}^{C C}-\pi_{1}^{C N}>0$. However, only area $\mathbf{C}$ satisfies the secondorder condition (S.O.C.) The other parameters here are $a=5, b=1, c=1, \phi=1$.

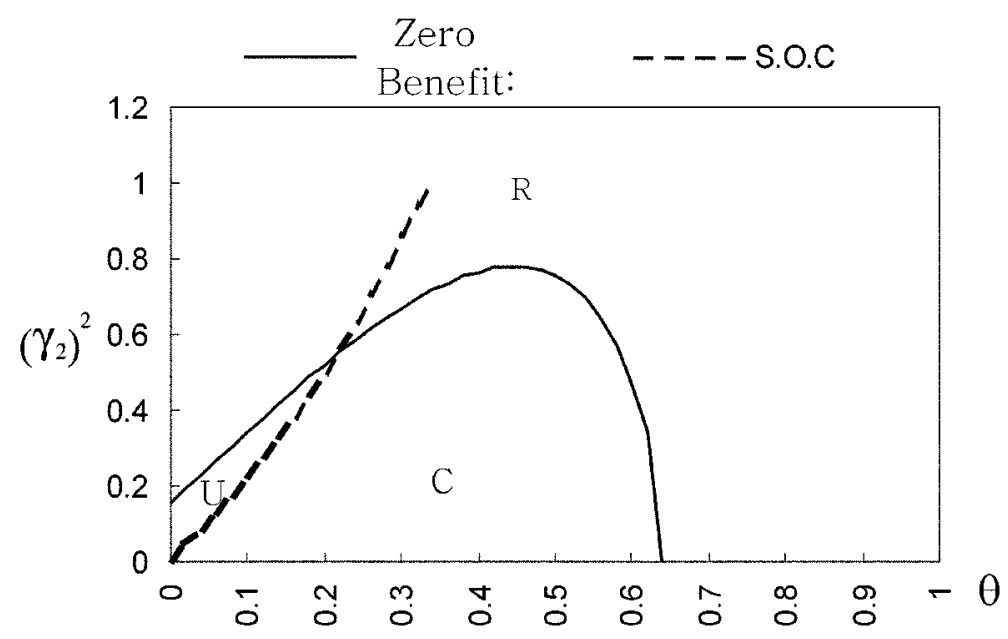

economic integration area $\left(\delta_{1}=\delta_{2}=\delta\right.$ and $\left.\gamma_{1}=\gamma_{2}=\gamma\right)$ and where the two governments have equal influence over the common trade policy $(\theta=1 / 2)$.

\section{Co-operative Lobbying in a FTA or a CU-An Example of the Symmetric Case with Unbalanced Bargaining Power}

This section uses an example of the symmetric case to show the conditions under which lobbyists have incentives to co-operate lobbying under the $\mathrm{CU}$ regime, but not under the FTA regime. It also represents the political environments in which lobbyists are willing to support a co-operation project. To simplify the comparison without a loss of generality, I only consider the case where $\gamma=0$, i.e. where lobbying the foreign government is invalid. In the numerical simulation I have the demand parameters: $a=5, b=1$, and the cost parameters $c=\phi=1$.

Figure 7 illustrates the combinations of different and that result in the different possibilities of co-operation in lobbying. Consider first the symmetric case under the FTA regime. Due to the symmetry of the setup, the domestic and the foreign firms have the same profits. Points under the horizontal dotted line at on this figure thus indicate that lobbyists will prefer to co-ordinate their lobbying, when 
Figure 7. A Comparison of Co-operative Lobbying in a FTA and a CU:

The Symmetric Case and $\gamma=0$.

Areas $\mathbf{C}_{i}$ and $\mathbf{C C}$ consist of the political environments for which firm $i$ is always willing to co-operate lobbying with the other firm under the FTA and the CU regimes. In area $\mathbf{A}_{i}$, firm $i$ co-operates under the FTA regime, but will not when the political integration of countries is changed to a $\mathrm{CU}$. The other parameters here are $a=5, b=1, c=1, \phi=1$.

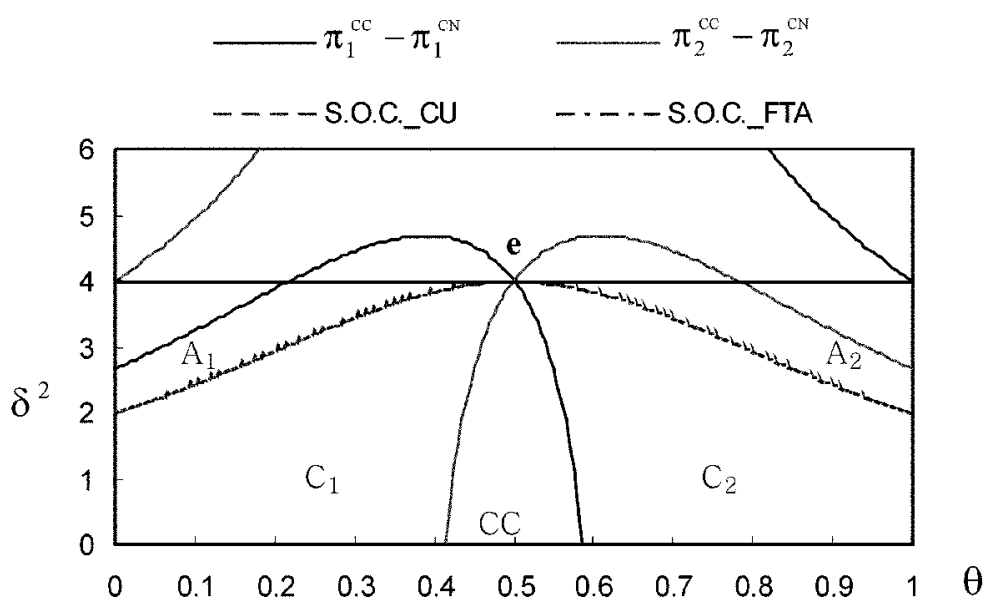

the second-order condition of co-operative lobbying is satisfied.

Next, consider the zero-benefit curve of co-operative lobbying for each firm under the CU regime. The zero-benefit curve of firm 1 is a pair of hyperbolas that locate at the upper-right in the top and the left-hand side in the bottom in this figure. Similarly, the other pair of hyperbolas on this graph depicts the zero-benefit curve for firm $2 .^{7}$ The combinations in the area under the dotted curve satisfy the second-order condition of co-operative lobbying for the $\mathrm{CU}$ regime. For political environments that lie in areas $\mathbf{C}_{i}$ and $\mathbf{C C}$, firm $i$ can be expected to co-operate in lobbying with the other firm under the $\mathrm{CU}$ regime.

Suppose the two governments decide to enhance their trading agreements from a FTA to a CU. In Figure 7, Areas $\mathbf{C}_{i}$ and $\mathbf{C C}$ consist of the combinations of $\delta^{2}$ and $\theta$ for which firm $i$ is always willing to co-operate in lobbying with the other firm under the FTA and the CU regimes. For the political situation that lies in area $\mathbf{A}_{i}$, firm $i$ will co-operate under the FTA regime, but will not when the political integration of countries is enhanced in a CU. In contrast, for environments in the area between $\delta_{2}=4 b \phi$ and $\delta^{2}=8 b \phi$, firm $i$ will not co-operate in lobbying either

\footnotetext{
${ }^{7}$ The relative expression of firm 2's net benefit function of co-operative lobbying can be found in Appendix D.
} 
under the FTA regime or under the $\mathrm{CU}$ regime. Point e corresponds to the numerical values of $\theta=1 / 2$ and $\delta=2$.

As shown in Figure 7, for political environments in area $\mathbf{C C}$ both firms will continue to undertake lobbying co-operatively, and see higher profits with the move from a FTA to a CU. The implication of the above is that the more equivalent influences in the formation of the $\mathrm{CU}$ tariff from the two governments are, the more likely firms will co-ordinate their lobbying under the $\mathrm{CU}$ regime. If the common trade policy is mainly influenced by one country, such a dominance may reduce the incentives of its own firms to co-operate in lobbying with the other firm. But, when politicians treat foreign lobbyists more like domestic ones (e.g. large $\gamma$ ), firms' zero-benefit curves of co-operative lobbying would be flatter (see Figures 4 and 5). In this case, the effect of the domination of one country over the other in the tariff-setting declines, and co-operation in lobbying is more feasible.

\section{Conclusion}

In my two-stage model, trade policy is endogenously influenced by lobbying pressures and politicians are assumed to be selfish. My model also allows for conditions for which foreign lobbying pressures can matter in the determination of trade policy, and tries to identify the conditions under which interest groups may co-operate in lobbying across countries. I have shown that either a higher lobbying sensitivity $\left(\gamma_{j}\right)$ to the foreign firm or a more susceptibility of politicians to lobbying $\left(\delta_{j}\right)$ are sufficient to lead to a higher tariff protection at the individual country level.

In the discrimination-asymmetric case under the FTA regime, the susceptibilities of the two governments to foreign lobbying pressures are different, but the domestic and the foreign politicians respond to lobbying with the same sensitivities. My results show that when the lobbying response $(\delta)$ factor is small, firms always have incentives to co-operate no matter how much politicians discriminate against foreign lobbyists. In contrast, if politicians are very susceptible to lobbying (a large $\delta$ ), the results appear to be ambiguous (see Figures 2 and 3).

Some comments on the model here are in order. Firstly, my results rely on the values of parameters employed in simulations, which should be interpreted qualitatively rather than quantitatively. In reality, it is obviously difficult to judge which levels of lobbying are high and which levels are low. Secondly, my model 
has attempted to comprehend the role of the political asymmetries in trade policy, particularly with regard to co-operative lobbying. The strategic interactions are not allowed for between firms such as explicit or tacit collusion. Thirdly, I model the relationship between lobbying and trade policy from the lobbyists viewpoint. Also, my model includes neither uncertainty nor asymmetric information.

\section{Acknowledgements}

Thanks are due to Professors Ron Smith, Stefan Szymanski and Sajal Lahiri for invaluable suggestions, and the National Science Council (Taiwan) for financial support of the research underlying this paper (No. 90-2911-I-309-001).

Received 4 January 2003, Accepted 3 April 2003

\section{Appendix}

\section{A. The First-Order Conditions of the Co-operative Case under a CU.}

$$
\begin{gathered}
\left(\theta^{2}\left(\delta_{1}\right)^{2}-2 b \phi\right) l_{11}+\theta^{2}\left(\delta_{1}\right)^{2} \gamma_{1} l_{21}+\theta(1-\theta) \delta_{1} \delta_{2}\left(\gamma_{2} l_{12}+l_{22}\right)=-(a-c) \theta \delta_{1} . \\
\theta^{2}\left(\delta_{1}\right)^{2} \gamma_{1} l_{11}+\left(\theta^{2}\left(\delta_{1}\right)^{2}\left(\gamma_{1}\right)^{2}-2 b \phi\right) l_{21}+\theta(1-\theta) \delta_{1} \delta_{2} \gamma_{1}\left(\gamma_{2} l_{12}+l_{22}\right)=-(a-c) \theta \gamma_{1} \delta_{1} . \\
\theta(1-\theta) \delta_{1} \delta_{2} \gamma_{2}\left(l_{11}+\gamma_{1} l_{21}\right)+\left((1-\theta)^{2}\left(\delta_{2}\right)^{2}\left(\gamma_{2}\right)^{2}-2 b \phi\right) l_{12}+(1-\theta)^{2}\left(\delta_{2}\right)^{2} \gamma l_{22}= \\
-(a-c)(1-\theta) \gamma_{2} \gamma_{2} . \\
\theta(1-\theta) \delta_{1} \delta_{2}\left(l_{11}+\gamma_{1} l_{21}\right)+(1-\theta)^{2}\left(\delta_{2}\right)^{2} \gamma_{2} l_{12}+\left((1-\theta)^{2}\left(\delta_{2}\right)^{2}-2 b \phi\right) l_{22}= \\
-(a-c)(1-\theta) \delta_{2} .
\end{gathered}
$$

By using Cramers rule, we can obtain the optimal amount of co-operative lobbying in the first stage under a CU. The solution to (A1) is shown in (13).

\section{B. The Net Profits from Co-operating Lobbying for Firm One under a} FTA.

The Symmetric Case: $\delta_{1}=\delta_{2}=\delta$ and $\gamma_{1}=\gamma_{2}=\gamma$.

$$
\pi_{1}^{F C}-\pi_{1}^{F N}=\frac{2 b \phi^{2}(a-c)^{2}\left(1+\gamma^{2}\right) \delta^{2}}{\left(4 b \phi-\left(1+\gamma^{2}\right) \delta^{2}\right)\left(8 b \phi-\left(1+\gamma^{2}\right) \delta^{2}\right)^{2}}, \quad r \in[0,1]
$$

The Discrimination-asymmetric Case: $\delta_{1}=\delta_{2}=\delta$ and $\gamma_{1} \neq \gamma_{2}$. 


$$
\begin{aligned}
\pi_{1}^{F C}- & \pi_{1}^{F N}=b \phi^{2}(a-c)^{2}\left(\frac{8 b \phi\left(2\left(\gamma_{1}\right)^{2}-1\right)-\left(3\left(\gamma_{1}\right)^{2}-1\right)\left(1+\left(\gamma_{1}\right)^{2}\right) \delta^{2}}{\left(\left(4 b \phi-\left(1+\left(\gamma_{1}\right)^{2} \delta^{2}\right)\left(8 b \phi-\left(1+\left(\gamma_{1}\right)^{2}\right) \delta^{2}\right)\right)^{2}\right.}\right. \\
& +\frac{8 b \phi\left(2\left(\gamma_{2}\right)^{2}-1\right)-\left(3-\left(\gamma_{2}\right)^{2}\right)\left(1+\left(\gamma_{2}\right)^{2}\right) \delta^{2}}{\left(\left(4 b \phi-\left(1+\left(\gamma_{2}\right)^{2} \delta^{2}\right)\left(8 b \phi-\left(1+\left(\gamma_{1}\right)^{2}\right) \delta^{2}\right)\right)^{2}\right.} \delta^{2}, \gamma \in[0,1]
\end{aligned}
$$

C. The Net Profits from Co-operating Lobbying for Firm One under a CU. The Symmetric Case: $\delta_{1}=\delta_{2}=\mathrm{d}$ and $\gamma_{1}=\gamma_{2}=\gamma$.

$$
\begin{gathered}
\pi_{1}^{C C}-\pi_{1}^{C N}=\frac{b \phi^{2}(a-c)^{2}}{2} \\
\left(\frac{4 b \phi\left(\left(2-\gamma^{2}\right)(1-2 \theta)+\left(1+\gamma^{2}\right) \theta^{2}\right)-\left(\left(3-\gamma^{2}\right)(1-2 \theta)+2\left(1+\gamma^{2}\right) \theta^{2}\right) \hat{A}}{((2 b \phi-\hat{A})(4 b \phi-\hat{A}))^{2}}\right) \delta^{2} \\
\gamma, \theta \in[0,1]
\end{gathered}
$$

where $\hat{A}=\left(\theta^{2}+(1-\theta)^{2}\right) \delta^{2}(1+\gamma)$.

The Discrimination-asymmetric Case: $\delta_{1}=\delta_{2}=\delta$ and $\gamma_{1} \neq \gamma_{2}$.

$$
\begin{gathered}
\pi_{1}^{C C}-\pi_{1}^{C N}=\frac{b \phi^{2}(a-c)^{2}}{2}\left(\frac{4 b \phi\left(\left(2\left(\gamma_{1}\right)^{2}-1\right) \theta^{2}+\left(2+\left(\gamma_{2}\right)^{2}\right)(1-\theta)^{2}\right)}{((2 b \phi-\bar{A})(4 b \phi-\bar{A}))^{2}}-\right. \\
\left.\frac{\left(\left(3\left(\gamma_{1}\right)^{2}-1\right) \theta^{2}+\left(3+\left(\gamma_{2}\right)^{2}\right)(1-\theta)^{2}\right) \bar{A}}{((2 b \phi-\bar{A})(4 b \phi-\bar{A}))^{2}}\right) \delta^{2}, \quad \gamma_{j}, \theta \in[0,1]
\end{gathered}
$$

where $\bar{A}=\left(\theta^{2}\left(1+\gamma_{1}\right)^{2}+(1-\theta)^{2}\left(1+\left(\gamma_{2}\right)^{2}\right)\right) \delta^{2}$.

D. Firm Twos Net Benefit from Co-operative Lobbying under a CU: The Symmetric Case.

$$
\begin{aligned}
\pi_{1}^{C C}- & \pi_{1}^{C N}=\frac{b \phi^{2}(a-c)^{2}}{2}\left(\frac{4 b \phi\left(\left(2 \gamma^{2}-1\right)(1-2 \theta)+\left(1+\gamma^{2}\right) \theta^{2}\right)}{((2 b \phi-\hat{A})(4 b \phi-\hat{A}))^{2}}-\right. \\
& \left.\frac{\left(\left(3 \gamma^{2}-1\right)(1-2 \theta)+2\left(1+\gamma^{2}\right) \theta^{2}\right) \hat{A}}{((2 b \phi-\hat{A})(4 b \phi-\hat{A}))^{2}}\right) \delta^{2}, \quad \gamma_{j}, \theta \in[0,1] ;
\end{aligned}
$$

where $\hat{A}=\left(\theta^{2}+(1-\theta)^{2}\right) \delta^{2}\left(1+\gamma^{2}\right)$. 


\section{References}

Baldwin, Robert E. (1986) The Political Economy of U.S. Import Policy, The MIT Press. Baldwin, Richard E. and A. Venables (1995) Regional Economic Integration, in G. Grossman and K. Rogoff, Eds., Handbook of International Economics, Vol. III, Elsevier Science Publishers B. V.

Bandyopadhyay, S. and H. Wall (1998) Customs Union or Free Trade Area? The Role of Political Asymmetries, Review of International Economics, 7, 665-72.

Bhagwati, J. N. (1980) Lobbying and Welfare, Journal of Public Economics, 14, 355-363.

Brainard, S. L. and T. Verdier (1994) Lobbying and Adjustment in Declining Industries, European Economic Review, 38, 586-595.

Brainard, S. L. and T. Verdier (1997) The Political Economy of Declining Industries: Senescent Industry Collapse Revisited, Journal of International Economics, 42, 221237.

Brock, W. A. and S. P. Magee (1978) The Economics of Special Interest Politics: the Case of the Tariff, American Economic Review, 68, 2, 246-250.

Cadot, O., De Melo, J. and M. Olarreaga (1996) Regional Integration and Lobbying for Tariffs against Non-members, CEPR Discussion Paper 1448.

Cassing, J. H. and A. L. Hillman (1986) Shifting Comparative Advantage and Senescent Industry Collapse, American Economic Review, 76, 3, 516-523.

Choi, Jay Pil (2001) Protectionist Response to Import Competition in Declining Industries Reconsidered, European Journal of Political Economy 17, 193-201.

De Melo, J., Panagariya, A. and D. Rodrik (1993) The New Regionalism: A Country Perspective, in J. De Melo and A. Panagariya, Eds., New Dimensions in Regional Integration, The Cambridge University Press.

Grossman, G. M. and E. Helpman (1994) Protection for Sale, American Economic Review, 84, 4, 833-850.

Hillman, A. L. (1982) Declining Industries and Political-Support Protectionist Motives, American Economic Review, 72, 5, 1180-1187.

Hillman, A. L. (1989) The Political Economy of Protection, Chur: Harwood.

Hillman, A. L. and H. W. Ursprung (1988) Domestic Politics, Foreign Interests, and International Trade Policy, American Economic Review, 78, 4, 729-745.

Hine, R. C. (1994) International Economic Integration, in D. Greenaway and L. A. Winters, Eds., Surveys in International Trade, Oxford: Blackwell.

Jovanovic, M. N. (1992) International Economic Integration: Limits and Prospects, London and New York: Routledge.

Krueger, A. O. (1974) The Political Economy of Rent-Seeking Society, American Economic Review, 64, 3, 291-303.

Krueger, A. O. (1997a) Free Trade Agreements versus Customs Unions, Journal of Development Economics, 54, 169-187.

Krueger, A. O. (1997b) Problems with Overlapping Free Trade Areas, in T. Ito and A. O. 
Krueger, Eds., Regionalism versus Multilateral Trade Arrangements, The University of Chicago Press.

Lipsey, R. G. (1960) The Theory of Customs Unions: A General Survey, Economic Journal, 70, 496-513.

Long, N.V. and N. Vousden (1991) Protectionist Response and Declining Industries, Journal of International Economics, 30, 87-103.

Mayer, W. (1984) Endogenous Tariff Formation, American Economic Review, 74, 5, 970985.

Moore, M. and S. M. Suranovic (1992) Lobbying vs. Administered Protection, Journal of International Economics, 32, 289-303.

Panagariya, A. and R. Findlay (1996) A Political-Economy Analysis of Free Trade Area and Customs Unions, in R. C. Feenstra, G. M. Grossman and D. Irwin, Eds., The Political Economy of Trade Policy, The MIT Press.

Peltzman, S. (1976) Towards a More General Theory of Regulation, Journal of Law and Economics, 19, 2, 211-240.

Richardson, M. (1993) Endogenous Protection and Trade Diversion, Journal of International Economics, 34, 309-334.

Richardson, M. (1994) Why a Free Trade Area? The Tariff Also Arises, Economics and Politics, 6, 79-96.

Rodrik, D. (1986) Tariffs, Subsidies, and Welfare with Endogenous Policy, Journal of International Economics, 21, 285-299.

Rodrik, D. (1995) Political Economy of Trade Policy, in G. Grossman and K. Rogoff, Eds., Handbook of International Economics, Vol. 3, North-Holland.

Stigler, G. J. (1971) The Theory of Regulation, Bell Journal of Economics and Management Science, 2, 3-21.

Viner, J. (1950) The Economics of Customs Unions, Ch. 4 in The Customs Union Issue, New York: Carnegie Endowment for International Peace. 